\title{
Interpretación nietzscheana del fenómeno estético
}

\section{Nietzschean Interpretation of the Esthetic Phenomenon}

Franz Mauricio Castro Barahona*

\section{Resumen}

Las reflexiones nietzscheanas sobre la razón y la sensibilidad como grandes fuerzas en tensión, la sensibilidad como liberadora de la existencia y la embriaguez cómo estado creativo por excelencia se presentan en este artículo mostrando como interpretar es un acto vital; así como lo es el crear para Nietzsche. De esta manera, un investigador gana una posición en el mundo y trasciende en la medida en que no solo se comprende a sí mismo, ni a una obra aislada y particular, sino al hombre en general. La creencia en el poder del hombre y la naturaleza: la unión de estas fuerzas para sentir la vida y mostrar lo bello del ser humano así como sus contradicciones, es el poder que la estética nietzscheana da al hombre frente a los ideales que lo alejan de la vida misma y no le permiten la posesión de la tierra. Es la liberación de todos los instintos para acabar con los ideales de la religión que es nociva para la vida. Aspecto enunciado ya por Habermas, en las formas de existir, de sujetos diferentes, que expresan una respuesta estéticamente fundada a la pregunta por la existencia.

\section{Palabras clave:}

Filosofía, vitalismo, arte, dionisio, Apolo, razón, naturaleza, Platón, Sócrates, cristianismo, pasiones, embriaguez, apariencia, racionalidad, nihilismo, voluntad de poder.

\section{Abstract}

Nietzsche builds up a reflection about reason and senses as strong forces on tension. Where the senses release human existence and drunkenness is the creative state for excellence. In this paper are shown the reflection and the interpretation acts, as a vital phenomenon created by Nietzsche himself. For this reason, an interpreter reaches a position in the world and transcends when there is not just an understanding of him or herself, of an art work, but also an interpretation of the human being in general. There is a believe on the power of man and nature, their union in order to life, that can show the beauty, the ugliness, and the contradictions of human being; this power is given to mankind on Nietzsche's special way of seeing art, and goes in the opposite way than ideas does; since they move men further away from life itself. Nietzsche faces religion hatred with senses release. This aspect is included in the question about existence in Habermas works as well.

\section{Key words:}

Philosophy vitalism, art, dionysus, Apolo, reason, nature, Plato, Sócrates, christianism, passions, drunkenness, appearance, rationalism, nihilism, will to power.

Artículo recibido el 29 de febrero de 2008 y aprobado el 12 de mayo de 2008

* Magíster en Literatura. Profesor del Departamento de Lenguas de la Universidad Pedagógica Nacional. franz78@hotmail.com 
La primera idea sobre el mundo que nos atrae de Friedrich Nietzsche es que no hay límite a la hora de comprender al hombre y todo lo que tradicionalmente llamamos productos culturales. La filosofía, el arte y la vida pierden sus fronteras y se convierten en una misma disciplina del ser y de la esencia de la vida. Por consiguiente, es importante dilucidar el vitalismo de Nietzsche clarificando su visión sobre el arte, el hombre, la vida y algunos otros aspectos que en definitiva se proyectan sobre un solo espectro: el hombre que vuelve a poseer la existencia.

Desde la Antigüedad clásica, la filosofía ha evidenciado que el destino humano es la resultante del entrecruzamiento de dos fuerzas en tensión o de dos poderes que gobiernan al hombre: el $\lambda o \gamma o \varsigma$ y la $\varphi v \sigma \iota \varsigma$, la razón y la naturaleza. En la cultura occidental la razón ha sido puesta como gobernadora de la naturaleza, pues está dotada de una lógica y de una intencionalidad que no posee la segunda. Por ella ha sido posible la institucionalización de la religión y del arte. Esta racionalidad intencional impone reglas de organización que la naturaleza no puede darse a sí misma, pues en su fluir cíclico (al que se subordinan las "leyes" naturales), carente de orden teleológico, rige el caos con imperio absoluto, pues la physis es el reino de la entropía y del azar.

En El Origen de la tragedia (1975), Nietzsche identifica a la razón con el dios griego Apolo, y a la naturaleza, con el dios Dionisio. Se dice que la tragedia tuvo un principio mítico en las celebraciones y ceremonias de tipo agrario que representaban la muerte y la vida en la naturaleza. Dionisio, dios del vino, era adorado a través de la danza, el trance y el éxtasis. Dionisio, acompañado de sátiros, quienes son las fuerzas de la naturaleza, pide a sus fieles no hablar de sacrificios y entregarse a la excitación sensual, sexual. Los sátiros son representados por machos cabríos, pues en ellos prepondera un marcado instinto sexual. El caos que esto instaura es ordenado por el contrapunto entre el canto y los diálogos que comienzan los sátiros. La evolución de esto conduce a la organización teatral que conocemos de la tragedia, en la cual se ha operado una fusión del principio dionisiaco y el principio apolíneo: la fuerza vital es lo que queda del culto a Dionisio, pero se nos transmite en un orden claramente enraizado en la figura del dios Apolo.

Para comprender mejor la relación filosófica entre la razón y la naturaleza, debemos hacer referencia también al mito de la caverna de Platón1. En él, su autor abre un sendero que marcará el decurso del pensamiento occidental hasta nuestros días, al prevenirnos contra el engaño de las apariencias que nos muestra el mundo físico. Todo lo que podemos afirmar sobre este mundo queda en el nivel de la opinión y, por tanto, su conocimiento no es real. El conocimiento verdadero deriva de la buena utilización de la razón, que nos permite llegar a ideas universales; formas eternas, sustancias que dan origen al mundo real.

Con esto, Platón quiso llegar a la esfera de lo humano, de forma tal que su teoría resultara válida en el campo de la moral. El hombre es hombre porque participa de la idea universal de humanidad. Así mismo, si una acción es justa, lo es porque participa de la idea de justicia, porque tiene algo en común ella. En fin, todo en el mundo sensible, en el mundo de las apariencias, obra así y está jerarquizado de forma que la primera más importante idea es la de Dios. La vida debe estar orientada a alcanzar la contemplación de esta idea. Por eso en ella nada vale si no está ordenado a alcanzar tal objetivo. La vida se llena de virtud cuando yo pongo todo al servicio de este fin último y suprimo aquello que pueda apartarme de él.

La tradición socrática y platónica enseña un conocimiento que se consigue a través del sufrimiento

1 El mito de la caverna describe a personas encadenadas en la parte más profunda de una caverna. Atados de cara a la pared, su visión está limitada y, por lo tanto, no pueden distinguir a nadie. Lo único que se ve es la pared de la caverna sobre la que se reflejan modelos o estatuas de animales que pasan y objetos que son llevados delante de una gran hoguera resplandeciente. Uno de los convictos se libera y sale a la luz del día=. Con la ayuda del Sol, esta persona ve por primera vez el mundo real y regresa a la caverna diciendo que las únicas cosas que han visto hasta ese momento son sombras y apariencias y que el mundo real los espera en el exterior si quieren liberarse de sus ataduras. El mundo de sombras de la caverna simboliza para Platón el mundo sensible o de las apariencias. La escapada al mundo soleado que se encuentra en el exterior de la caverna simboliza la transición hacia el mundo real, el universo de la existencia plena y perfecta, que es el objeto propio del conocimiento. 
y el dolor. A la verdad platónica se llega liberándose de la carne, de la sensibilidad y de las tendencias naturales: conocer implica agobiar al ser humano. La tragedia griega nació como protesta a esta concepción del conocimiento heredada de las epopeyas homéricas (el periplo de Ulises podría valer como metáfora de la ardua búsqueda de la verdad), pero a su vez fue atacada por la doctrina de la verdad de Sócrates y Platón. En la tragedia se observa al hombre como juguete del destino; los dioses son incapaces de dar una respuesta al sufrimiento humano y además lo cargan con un destino ineludible, una condena merecida. Tanto el racionalismo griego como la religión helénica habían condenado al hombre al olvido de sí mismo; la tragedia, entonces, surgió como el alivio a este olvido (1975: 53) y como el castigo a la pretensión de sabiduría de los hombres, mientras que la decadencia de la tragedia bajo los ataques de la filosofía socrático-platónica es el precio pagado por la posesión de la naturaleza.

La visión platónica del mundo está fundada en el principio apolíneo. Apolo está en la esfera del mundo real (es decir, el plano de las ideas). Apolo es cifra de los universales platónicos: él es -nos dirá Nietzsche-, el dios de la armonía, del esplendor de la justicia, de la serena sabiduría, el dios de la forma en el arte, el vencedor ajeno ya al mundo del dolor (1975: 23). Es el dios que nos recuerda lo finitos que somos y nos pone en la tarea de alcanzar su efigie eterna, el rostro impasible de la verdad, que solo podría conquistarse tras arduas bregas.

Dionisio, en cambio, es el dios de la embriaguez, representa la naturaleza y su fuerza; por eso no está en la esfera de la razón. Dionisio incita al hombre al olvido de sí mismo, anulando el estado consciente que caracteriza a la razón (1975: 24). Así como en la tragedia griega Dionisio dio origen al coro, encargado de advertir a los personajes acerca de su labilidad, es él quien recuerda al hombre la necesidad de establecer una alianza con sus congéneres para soportar la vida.

La embriaguez permite al hombre sentirse dios, rompe el lazo que le impide trascender su finitud y liberarse para alcanzar lo que los dioses le han robado: el gozo de la vida.
El hombre no es ya un artista, es una obra de arte; el poder estético de la naturaleza entera por la más alta beatitud y la más noble satisfacción de la unidad primordial, se revela aquí bajo el estremecimiento de la embriaguez (1975: 28).

La embriaguez es el estado que posibilita la identificación del hombre con las fuerzas primordiales del mundo, reclamadas por nuestra naturaleza, pues somos seres que, más allá del ideal platónico de la verdad, necesitamos de la apariencia, es decir, de la vida que poseemos en la existencia física. Este estado permite al sujeto estar despejado de obstáculos y pasar los límites que le impone la razón. Esta actitud consiente al hombre que se encuentre consigo mismo en la conexión con la naturaleza, pues el deseo exacerbado de contemplar la verdad eterna e inmutable lo ha llevado a percibir su existencia concreta como una condición determinada por la fealdad y el absurdo.

Es aquí donde entra el arte. Este es un bálsamo saludable que cambia el hastío en imágenes que ayudan a soportar la vida. En este sentido, hay muchas formas en el arte que se convierten en imágenes reales de la vida, capaces de sustituir la idea para traerla al mundo concreto del hombre (1975, p. 57). En la tragedia, por ejemplo, el coro opera como el sustentador de estas imágenes:

\footnotetext{
Desde este punto de vista, podemos llamar al coro, bajo su forma primitiva en la tragedia original, la imagen reflejada del hombre dionisiaco mismo, y este fenómeno no lo podemos hacer patente de mejor modo que por el ejemplo del actor, que, cuando está verdaderamente inspirado, ve aflorar ante sus ojos la imagen casi material del papel que interpreta. El coro de sátiros es, ante todo, una visión de una multitud dionisiaca, como a su vez, el mundo de la escena es una visión del coro de los sátiros; el poder de esta visón es bastante fuerte para deslumbrar la mirada y hacerla insensible a la impresión de la "realidad", al espectáculo de los hombres civilizados, sentados en círculo sobre las graderías. (1975: 57)
}

El dios del vino es ante todo, en sus actos y palabras, un individuo expuesto al error, al deseo y al sufrimiento, y la superación de este estado pasio- 
nal, desde la óptica socrática, sólo puede lograrse mediante un proceso de conocimiento que se da a través de la virtud y la moral. El conocimiento dionisiaco se determina por la actitud fundamental de la embriaguez: exageración de los instintos. El conocimiento socrático, en cambio, se basa en la conciencia de la verdad, según la máxima de que sólo lo que es consciente puede ser bello. Esta actitud racional impuesta por Sócrates llevó a la muerte del arte que reconocía en sí mismo la naturaleza.

Sócrates invierte los papeles del conocimiento:

Mientras que en todos los hombres el instinto, en lo que se refiere a la génesis de su creación, es precisamente la fuerza poderosa, positiva y creadora, y la razón consciente, una función crítica, desalentadora, en Sócrates el instinto se revela como crítico y la razón es creadora (1975: 83).

Para Platón, discípulo de Sócrates, el arte antiguo era la imitación de una apariencia y, por tanto, de un orden inferior, en contra de la virtud, que es la sabiduría y permite al hombre ser realmente feliz.

Nietzsche, en este estudio genealógico del pensamiento griego, entiende que la razón liga al hombre a la vida como idea, mientras que el instinto lo conecta con la naturaleza, donde residen la vida y la muerte del ser concreto. Cuando desaparece la tragedia, nace la ciencia. Esta es un producto del temor y un refugio contra el pesimismo, un ingenioso expediente contra la verdad y, moralmente hablando, algo así como miedo e hipocresía y, hablando inmoralmente, astucia.

En los griegos hay un deseo de belleza, de fiestas, de jolgorios de cultos nuevos, no de tristeza, miseria, melancolía o dolor. Frente a este deseo en ellos hay una inclinación a la crueldad, al terror, al misterio, al vacío, a la fatalidad anidada en el fondo de la existencia. Un pesimismo enfrentado a la vitalidad está en una antítesis muy original. Nietzsche piensa que ese pesimismo es una actitud crítica declarada a la existencia misma.

El arte es la actividad esencialmente metafísica del hombre; la existencia del mundo no está probada más que como fenómeno estético. La vida el mundo, todo lo que el hombre construye y él mismo, son arte; pueden ser arte.
En el contexto religioso, la existencia es justificada por la idea de Dios. En particular, en la tradición judeocristiana la vida es vista como un camino que debe ser dispuesto en orden a alcanzar la verdad y la divinidad. Según el cristianismo convencional, el sufrimiento humano es complemento de los padecimientos redentores del dios hecho hombre y, por eso, muy valedero para alcanzar la eternidad.

Por esta disposición que le es esencial, Nietzsche encuentra a la religión hostil a la vida, rabiosa y satírica, repugnante para los instintos vitales:

El odio del "mundo" anatema de las pasiones, el miedo a la belleza y a la voluptuosidad, un más allá futuro, inventado para denigrar mejor el presente, un deseo de aniquilación, de muerte, de reposo, en el fondo hasta el sábado de los sábados (1975: 17).

El hombre ha cedido al cansancio de la vida en el camino a la racionalidad. Nietzsche cree que el sabio siempre ha dudado de la vida, sus palabras imprimen dolor y melancolía al vivir y recuerda a Sócrates, quien al momento de su ejecución ofrece un gallo como ofrenda por recibir la cura a su enfermedad2; esta no es más que la muerte: si la muerte es la cura a la enfermedad que es vivir (1984: 37).

Esta actitud negativa frente a la vida se genera en torno a la racionalidad. La verdad a cualquier precio, la vida lúcida, fría, previsora, consciente, sin instinto ha mostrado ser otro tipo de enfermedad en la que se combate a los instintos.

\section{Aniquilar las pasiones y apetitos meramente para prevenir su estupidez y las consecuencias desagradables de ésta es algo que hoy nos parece meramente como una estupidez (1984: 54).}

$\mathrm{El}$ aniquilamiento de las pasiones es un aspecto que quiere corregir Nietzsche. En general se cree que ellas son un obstáculo que no le permite crecer al hombre. Ellas son contrarias a la ciencia, que se convierte en el valor más alto para la humanidad.

2 Véase Fedón, 118a: “Ya estaba frío bajo el vientre, cuando Sócrates se descubrió, pues estaba cubierto con un velo, y dijo, y estas fueron sus últimas palabras: Critón, debemos un gallo a Asclepio; pagádselo y no lo descuides." En Atenas se ofrecía un gallo a Asclepio por aquellos que habían estado enfermos y recobrado la salud. 
Este autor ve el cansancio que produce correr detrás de la verdad absoluta cuando no existen sino verdades relativas sobre cada espacio vital. La tarea que Nietzsche se propone es ardua y extensa, pues han pasado más de dos mil años después de establecer estas pretendidas verdades que tanto la filosofía como la religión han alimentado.

La Iglesia combate a la pasión con la extirpación en todos los sentidos de la palabra: su medicina, "su cura", es el castradismo. No pregunta jamás: ¿cómo espiritualizar, embellecer, divinizar un apetito?... Pero atacar las pasiones en su raíz significa atacar a la vida en su raíz: la praxis de la Iglesia es hostil a la vida (1984: 54).

Nietzsche considera que esta actitud es una defensa contra la debilidad de la voluntad de los frágiles, que son incapaces de imponerse moderación en el apetito. El hombre debe ser capaz de hacer del instinto la fuerza que completa la existencia; el hombre debe llevar el instinto a obrar como la fuerza que lo conecta a la naturaleza y a su poder (Macht). Obrar de manera contraria es huir por miedo y debilidad.

La espiritualización de la sensualidad se llama amor. Ella es un gran triunfo sobre el cristianismo. Otro triunfo es nuestra espiritualización de la enemistad (1984: 55).

El hombre debe aceptar las implicaciones de su instintividad connatural; no temerles, pues este temor lo ha llevado a vivir frágilmente. Si es posible el amor, también lo es el odio. En efecto, odiar hace parte de la naturaleza humana y en este sentimiento también anida la fuerza, aquella fuerza que se da plenamente en el arte, donde se expone la plenitud dinámica de las cosas y a la vez se refleja el poder del hombre.

Para que haya arte, para que haya un hacer y contemplar estético, resulta indispensable una consideración filosófica previa: la embriaguez. La embriaguez tiene que haber intensificado primero la excitabilidad de la máquina entera: antes de esto no se da arte ninguno. Todas las especies de embriaguez, por muy distintos que sean sus condicionamientos, tienen la fuerza de lograr esto: sobre todo la embriaguez de la excitación sexual, que es la forma más antigua y originaria de embriaguez. Asimismo la embriaguez de que van seguidos todos los apetitos grandes, todos los apetitos fuertes; la embriaguez de la fiesta, de la rivalidad, de la pieza de virtuosismo, de la victoria de todo movimiento extremado; la embriaguez de la crueldad; la embriaguez de la destrucción; la embriaguez debida a ciertos influjos meteorológicos, por ejemplo la embriaguez primaveral; o la debida al influjo de los narcóticos; por fin, la embriaguez de la voluntad, la embriaguez de una voluntad sobrecargada y henchida. Lo esencial de la embriaguez es el sentimiento de plenitud y de intensificación de la fuerzas. De ese sentimiento hacemos partícipes a las cosas, las constreñimos a que tomen de nosotros, las violentamos. idealizar es el nombre que se da a ese proceso. Desprendámonos aquí de un prejuicio: el idealizar no consiste, como se cree comúnmente, en un sustraer o restar, lo pequeño, lo accesorio. Un enorme extraer los rasgos capitales es, antes bien, lo decisivo, de tal modo que los demás desaparezcan ante ellos (1984: 90-91).

La razón, en un impulso protector, estableció valores supremos ante lo natural. Estos pretenden suplantar el instinto y durante milenios han creado en el imaginario colectivo ideas que ponen la vida por debajo de conceptos como dios, eternidad, cielo, virtud, pensamiento, psique, espíritu universal, en fin, conceptos abismalmente alejados del hecho concreto de vivir.

Estas ideas han generado cansancio y desconfianza, y a ellas se han sumado, en tiempos más recientes, otros ideales seculares, igualmente basados en la supremacía de la razón, como la fraternidad, el bien común, la libertad, la justicia, y otros símbolos propios de la modernidad, desvirtuados hoy, en plena época posmoderna, por una posición nihilista ante la historia: la no creencia en nada, tras la refutación, ya histórica, ya filosófica, de todos los valores supremos de la racionalidad.

El nihilismo es otro concepto importante en el pensamiento de Nietzsche en el que podemos encontrar utilidad: el hombre, al quedar desprovisto de las herramientas metafísicas que han hipertrofiado 
su razón, ha quedado a merced de sus propias fuerzas. Si sabe de ello, está en capacidad de hacer nacer de la actitud nihilista un ser con la fuerza de transformar el mundo. Si el nihilista simplemente refuta los valores supremos válidos por el hecho de poner en duda su veracidad y no hace de esta posición una brega por fomentar nuevos valores que refuercen la vida, su actitud no es más que el vértice de donde se lanza al descenso final y a la destrucción irreversible: el nihilismo se reduce a aniquilación.

Pero para Nietzsche el nihilismo no solo significa decadencia, fatalidad y destrucción, sino, sobre todo, un proceso histórico que impulsa un surgimiento creativo. El primer paso es el movimiento que consideramos opuesto al nihilismo de la decadencia y es la transvaloración de todos los valores. Nietzsche entiende por valores las realidades y leyes que la religión y la moral han puesto como norma para la vida. La libertad que el hombre necesita para alcanzar el proceso creador se da en esta corriente de destrucción y nueva creación que va contra los valores establecidos. Este proceso se convierte en el desarrollo de la voluntad de poder.

Hay, pues, dos momentos o dos formas en que podría obrarse desde una actitud nihilista. Es un proceso en "V". En el primer momento, la caída, está el replantearse de un modo crítico todo lo establecido como verdad. Después de esto, en el segundo momento, se asciende proponiendo nuevos valores que pretenden transformar la vida y convertir todo alrededor en propiedad del hombre. Ello se alcanza con la voluntad, “voluntad de ser dueño de...", que va más allá del simple poseer, pues se da como afecto, pasión, sentimiento, orden... Veamos:

La voluntad es en sí creadora y destructiva al mismo tiempo. Dominar-más-allá-de-sí es siempre también aniquilar. Todos los momentos de la voluntad a los que se ha aludido -el más-allá-de-sí, el acrecimiento, el carácter de orden, el crear, el afirmarse- hablan con claridad suficiente como para que pueda reconocerse que la voluntad es en sí misma voluntad de poder; poder no quiere decir otra cosa más que la realidad efectiva de la voluntad (Heidegger, 2000: 69).
La voluntad es positiva, es la fuerza que define al hombre, es el ser que posee de forma real y por el cual se define en lo humano. Para Nietzsche es claro que el hombre a lo largo de la historia se ha negado esa fuerza de sentir. Es la voluntad de existir que va en un tráfico opuesto a lo que afirma, ha sido impulsado por la razón y la religión; aquellos sabios que han dudado de la existencia y aquella religión que predica el cielo y no la vida terrena desgastaron esa fuerza que hoy se restaura. La convirtieron en amor sumiso para llegar furtivamente al poderoso; en sentimiento de deber que es un consuelo que ilusoriamente pone al hombre en un rango de superioridad moral frente al otro.

La razón, el dios occidental debe cesar su paso por la vida; el mismo hombre debe morir para que nazca el superhombre capaz de restaurar la fuerza vital como rectora de la existencia. Este es un paso definitivo y radical. Tal como lo expone Nietzsche en La gaya ciencia:

¿No habéis oído hablar de ese hombre loco que, en pleno día, encendía una linterna y echaba a correr por la plaza pública, gritando sin cesar, "busco a Dios, busco a Dios"? Como allí había muchos que no creían en Dios, su grito provocó la hilaridad. “Qué, ¿se ha perdido Dios?”, decía uno. “Se ha perdido como un niño pequeño?", preguntaba otro. “ ¿O es que está escondido? ¿Tiene miedo de nosotros? ¿Se ha embarcado? ¿Ha emigrado?” Así gritaban y reían con gran confusión. El loco se precipitó en medio de ellos y los traspasó con la mirada: “¿Dónde se ha ido Dios? Yo os lo voy a decir”, les gritó. ¡Nosotros lo hemos matado, vosotros y yo! ¡Todos somos sus asesinos! Pero, ¿Cómo hemos podido hacer eso? ¿Cómo hemos podido vaciar el mar? ¿Y quién nos ha dado la esponja para secar el horizonte? ¿Qué hemos hecho al separar esta tierra de la cadena de su sol? ¿Adónde se dirigen ahora sus movimientos? ¿Lejos de todos los soles? ¿No caemos incesantemente? ¿Hacia adelante, hacia atrás, de lado, de todos lados? ¿Hay aún un arriba y un abajo? ¿No vamos como errantes a través de una nada infinita? ¿No nos persigue el vacío con su aliento? ¿No hace más frío? ¿No veis oscurecer, cada vez más, cada vez más? ¿No es necesario encender linternas 
en pleno mediodía? ¿No oímos todavía el ruido de los sepultureros que entierran a Dios? ¿ $\mathrm{Nada}$ olfateamos aún de la descomposición divina? ¡También los dioses se descomponen! ¡Dios ha muerto y nosotros somos quienes lo hemos matado! ¿Cómo nos consolaremos, nosotros, asesinos entre los asesinos? Lo que el mundo poseía de más sagrado y poderoso se ha desangrado bajo nuestro cuchillo. ¿Quién borrará de nosotros esa sangre? ¿Qué agua podrá purificarnos? ¿Qué expiaciones, qué juegos nos veremos forzados a inventar? ¿No es excesiva para nosotros la grandeza de este acto? ¿No estamos forzados a convertirnos en dioses, al menos para parecer dignos de los dioses? No hubo en el mundo acto más grandioso y las futuras generaciones serán, por este acto, parte de una historia más alta de lo que hasta el presente fue la historia. Aquí calló el loco y miró de nuevo a sus oyentes; ellos también callaron y le contemplaron con extrañeza. Por último, arrojó al suelo la linterna, que se apagó y rompió en mil pedazos: "He llegado demasiado pronto, dijo. No es aún mi hora. Este gran acontecimiento está en camino, todavía no ha llegado a oídos de los hombres. Es necesario dar tiempo al relámpago y al trueno, es necesario dar tiempo a la luz de los astros, tiempo a las acciones, cuando ya han sido realizadas, para ser vistas y oídas. Este acto está más lejos de los hombres que el acto más distante; y, sin embargo, ellos lo han realizado (1974: 95-96).

Es muy interesante la posición del loco, quien sale a buscar a Dios y se encuentra con que nadie sabe dónde está. Él es el ebrio que ha salido en pleno día con la luz de la razón (que es inútil) a mostrar la imposibilidad de los hombres de dar respuestas; dios que es la inmensidad del mar y el horizonte, el soporte de la tierra, la razón de lo humano y lo terrestre, está muerto, y entonces, ¿qué será del hombre? Sí, él se encuentra en un momento privilegiado de la historia y solo él ha reconocido esa realidad, es un profeta fuera de su tiempo.
Loco o ebrio, esta metáfora nos muestra la fuerza de la que habla Nietzsche. El hombre indefenso que asume la nueva historia en la cual es dios de sí mismo.

El arte juega un papel vital en la nueva posición de los valores y, por ende, también el artista.Él es este personaje a quien el sentimiento de embriaguez le permite aumentar su fuerza (Nietzsche, 1981: 430). La fuerza se identifica con la voluntad de crear. Ser artista es poder crear (Heidegger, 2000: 74). Ser artista es la forma más transparente de la vida. El arte es la auténtica tarea de la vida, la tarea metafísica de la vida. El arte es decir sí a lo sensible, sí a aquello que no es verdadero; y este sí es lo que nos permite sobrevivir a la verdad.

Somos seres corporales y a la esencia del ser le pertenece el sentimiento en cuanto sentirse, "no tenemos un cuerpo como si lleváramos una navaja en el bolsillo" (Heidegger, 2000: 102), sino que lo tenemos para sentirlo y ser nosotros mismos. Esta nueva posición ofrece nuevas fuerzas para ir más allá de sí, para crear y recrear. La embriaguez significa lo contrario del cansancio, del agotamiento de "aquellos bajo cuya mirada la vida sufre" (Nietzsche, 1984: 37).

El arte, y la vida misma como arte, no puede estar sometido más a la razón y a la religión, porque no hay una meta ni un objetivo final trascendentes. El principio y fin están en el hombre que se autoposee una y otra vez en un eterno retorno hacia su fuerza esencial, o fuerza creativa. Este ir y venir que revela al hombre también posibilita que las cosas manifiesten lo que son.

La obra de arte muestra la fuerza del hombre, en cuanto es síntoma de la sobreabundancia de vida. El arte debe embellecer y, al mismo tiempo, velar el lado oscuro de la existencia y permitir que el artista se trascienda a sí mismo y se funda en armonía con la naturaleza. \1 


\section{Bibliografía}

Ferrater Mora, J. (2004). Diccionario Filosófico. Vol. II (E-J). Barcelona: Ariel, pp.1270-1282.

Heidegger, Martin. (2000).Nietzsche I. Madrid: Destino.

Heidegger, Martin.(1974). La gaya ciencia. Medellín: Bedout.

Heidegger, Martin. (1975). El Origen de la Tragedia. Madrid: Espasa Calpe.

Heidegger, Martin. (1981). La voluntad de poderío. Madrid: Biblioteca Edaf.

Heidegger, Martin. (1984). Crepúsculo de los ídolos o Cómo se filosofa con el martillo. Madrid: Alianza.

Nietzsche, Friedrich. (1997). Consideraciones intempestivas. Madrid: Alianza.
Nietzsche, Friedrich. (2000). Así habló Zaratustra. Madrid: Edimat Libros.

Nietzsche, Friedrich. (2001). El origen de la tragedia México: Porrúa.

Nietzsche, Friedrich. (2001). La ciencia jovial: la gaya scienza. Madrid: Biblioteca Nueva.

Sennett, Richard.(1997). Carne y Piedra. Madrid: Alianza.

Vattimo, Giani.(1992). Hermenéutica nieva Coiné. Ética de la interpretación. Barcelona: Paidós.

Zarone, Giuseppe. ( 1993). Metafísica de la ciudad: encanto utópico y desencanto metropolitano. Valencia: Pre-Textos-Universidad de Murcia. 